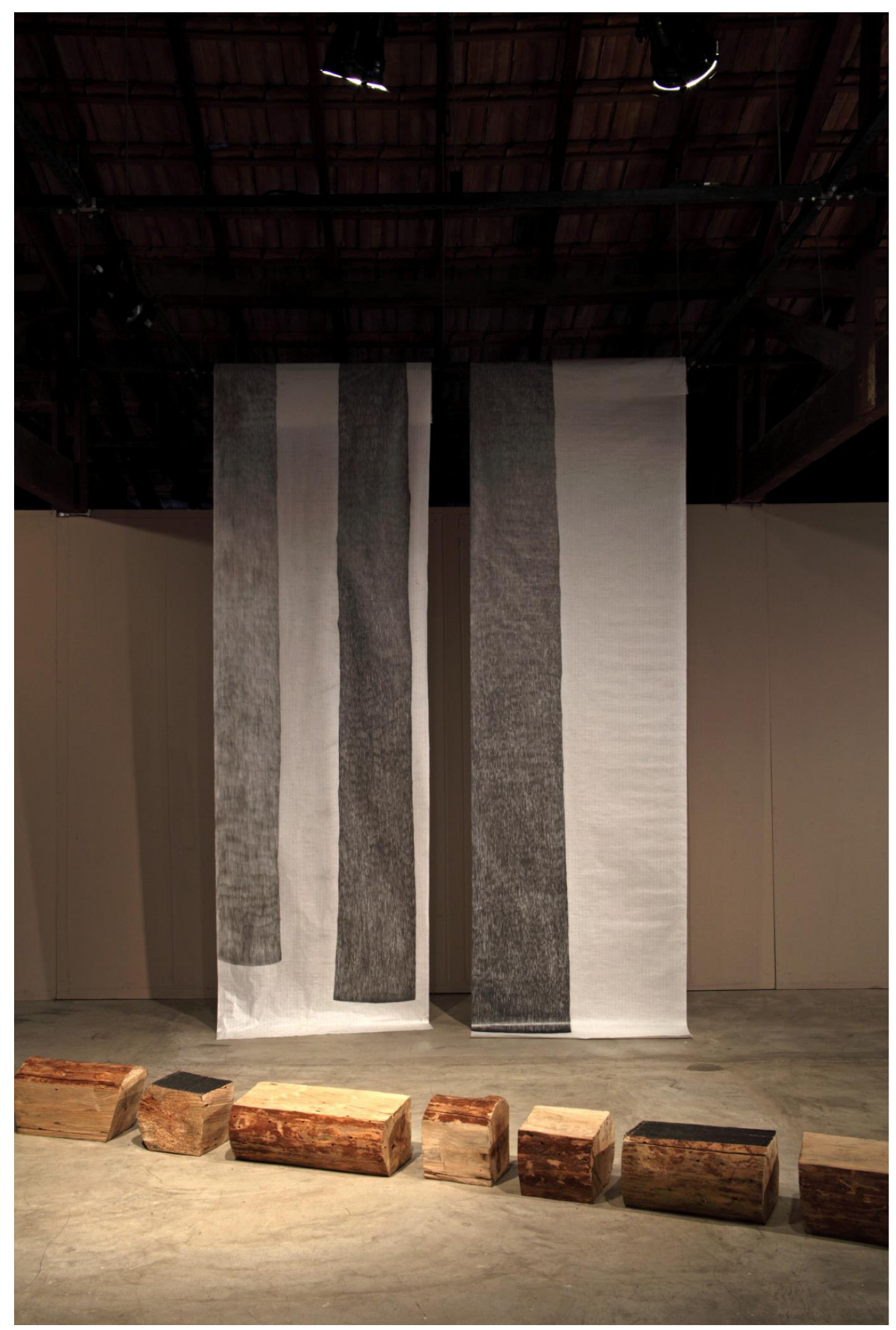

Júnia Penna. Corte/Mato/Mata e Aleia, 2015. Grafite s/papel japonês e madeiras, dimensões variáveis. Fotografia Wilton Montenegro. 10.12957/concinnitas.2019.44882 


\title{
ARQUITETURA DA PAISAGEM
}

\author{
Júnia Penna ${ }^{1}$
}

\begin{abstract}
Resumo: 0 homem ao vivenciar a paisagem é por ela ativado. Em "Arquitetura da Paisagem" investigo o modo como essa temática se manifesta na minha produção artística. $\mathrm{Na}$ construção do pensamento busco estabelecer conexões com concepções desenvolvidas por Anne Cauquelin, Jean-Marc Besse e Augustim Berque que refletem sobre a noção da paisagem na atualidade.
\end{abstract}

Palavras Chaves: arte contemporânea, percepção, paisagem, natureza.

\section{LANDSCAPE ARCHITECTURE}

\begin{abstract}
When people experience the landscape, they are activated by it. In "Landscape Architecture" I investigate the way this theme manifests itself in my artístic production. In the thought construction, I try to establish connections with conceptions developed by Anne Cauquelin, Jean-Marc Besse and Augustin Berque, who reflect about the notion of landscape nowadays.
\end{abstract}

Key words: contemporary art, perception, landscape, nature.

\footnotetext{
1 Júnia Penna - Belo Horizonte, 1966. (Vive e trabalha em Belo Horizonte). Professora do Departamento de Artes Plásticas da Escola Guignard - UEMG. Doutora pelo PROGRAMA de PÓSGRADUAÇÃO em ARTES - PPGARTES / UERJ, 2018; Mestre em Artes Visuais pela EBA/UFMG, 2003; Bacharel em Desenho pela Escola de Belas Artes-UFMG, 1991. Participa do ateliê coletivo Galpão EMBRA em Belo Horizonte entre 1989 e 1998. Em 2005 recebe bolsa da Pollock-Krasner Foundation. Entre as principais exposições individuais destacam-se BREU, Galeria de Arte da Cemig, BH, (2011); Júnia Penna, Gesto Gráfico Galeria de Arte, BH (2001). Entre as principais coletivas destacam-se Jardim Atlântico, Paço Imperial, RJ (2018); Jardim Atlântico, Colégio das Artes, Coimbra, Portugal (2017); ProjetoPlantaBaixa, (2017); Espaço Tom Jobim, Jardim Botânico, RJ (2015) Campo Branco, Centro Cultural Banco do Nordeste, Fortaleza (2012); Geometria Impura, Centro de Arte Hélio Oiticica, Rio de Janeiro (2010/11), Museu de Arte da Bahia, Salvador, MAM - BAHIA (2009) e Palácio das Artes, BH (2006).
} 
“[...] para mim, estar na natureza é uma forma de religião imediata." (Hamish Fulton).

Francesco Careri aponta que a atividade da arquitetura, desde o seu primórdio, provém de duas experiências distintas do homem sobre a extensão da terra. Uma delas ocupa e constrói o espaço de modo físico; já a outra resulta da movimentação e de deslocamentos de grupos humanos sobre a superfície terrestre. 0 ato de caminhar traduz-se então como ação que constrói "simbolicamente o espaço". Construção nômade, efêmera, que não deixa rastros. No entanto, a maior parte das experiências e atividades humanas sobre o substratum da terra deixam marcas. Marcas que muitas vezes se inscrevem no ambiente como vestígios permanentes. A superfície terrestre, portanto, encontra-se em contínuo estado de transformação e a ação do homem sobre o espaço onde ele vive promove constantes modificações na "paisagem" da terra.

$\mathrm{Na}$ minha pesquisa plástica, paisagens naturais são referências para o desenvolvimento de proposições artísticas. Realizo também intervenções, de carácter temporário, em áreas verdes que se apresentam como territórios de respiração entre os blocos de concreto que configuram os centros urbanos. Frente a essas proposições plásticas investigo como a ideia de paisagem e de natureza atravessa um grupo de obras. Na construção do pensamento busco dialogar com reflexões que se ocupam dessas temáticas provenientes do campo da filosofia, da sociologia e da geografia.

Diante da complexidade e da amplitude desses temas na atualidade, tenho como parâmetro o pensamento do sociólogo Georg Simmel, dos filósofos Jean-Marc Besse e Anne Cauquelin e, ainda, do geógrafo Augustin Berque, que articulam olhares distintos sobre a noção de paisagem e de natureza no território da cultura, da pintura, da geografia e da filosofia. Augustin Berque prioriza o aspecto relacional da paisagem. Já Anne Cauquelin discute a ideia da paisagem como equivalente à 
natureza. Jean-Marc Besse, por sua vez, entremeia filosofia e geografia ao refletir sobre o percurso da inserção da paisagem na ciência geográfica.

As aproximações entre o campo da arte e a esfera da geografia estão presentes desde o surgimento do termo "paisagem". 0 pintor e o geógrafo partilham do mesmo objeto de representação: a paisagem. Jean-Marc Besse observa que "o vocabulário utilizado no século XVI, para descrever as representações geográficas, era idêntico àquele utilizado para a pintura de paisagem". ${ }^{\mathrm{I}}$ Nesse sentido, o discurso geográfico é, então, muitas vezes permeado pelo léxico das artes visuais. Um exemplo é a concepção plástica que Vidal de La Blanche, fundador da Escola Francesa de Geografia, possui em relação à realidade geográfica. La Blanche compreende o substratum terrestre como um lugar receptivo à impressão de forças de circulação. De acordo com o seu olhar, a superfície da terra apresenta-se "como um substrato, uma espécie de massa plástica que pode acolher todas as inscrições". "II No entanto, as proximidades entre estes territórios de conhecimento e cultura não se reduzem apenas às correspondências terminológicas.

Outro campo de aproximação entre a arte e a geografia pode ser estabelecido no olhar distanciado, que gera a pintura tradicional da paisagem, bem como na representação cartográfica de um determinado território. 0 pintor, ao introduzir elementos naturais (rochas, árvores, rios, construções) na superfície do quadro, procura abarcar a extensão do ambiente. Tal como na representação da terra pela cartografia moderna a pintura da paisagem busca inscrever em um espaço, com limites pré-estabelecidos, o sentido de totalidade. Besse aponta que a aproximação entre a cartografia e a pintura de paisagem deve-se ao fato de que ambas as linguagens compartilham o mesmo objeto, discurso e também meios formais.

Geógrafos, filósofos e historiadores da arte concordam que a noção da paisagem surgiu no Ocidente no período do Renascimento Europeu. No entanto, Augustin Berque observa que a ideia da paisagem já se manifestava na China do século IV. Tal pensamento pode ser constatado no tratado Introdução à pintura de paisagem, escrito por Zong Bing. Entretanto, na concepção chinesa, a paisagem era concebida 
como uma forma material, que tenderia ao espírito, distanciando-se, assim, do pensamento moderno sobre o tema.

No livro A Filosofia da Paisagem, de 1913, George Simmel comenta que a ideia da paisagem surgiu concomitante à um processo de transformação da maneira como o sujeito se relaciona com o sentido de totalidade. Momento em que o indivíduo se descola do todo ao seu redor e passa a exercer um olhar que o permite distanciar-se do seu entorno. Desse modo, posiciona-se diante e não mais em meio ao mundo no qual se inscreve. Identifica-se, ainda, como um ser separado do que era entendido desde os antigos por Natureza: "a cadeia infindável do que existe, dos processos de formação, transformação e aniquilação das formas e seres, articulando-se em continuidade espaciotemporal". III

A paisagem natural como referente surgiu no meu percurso artístico ainda no final da década de 1990. Foi no trabalho Breu - que teve o início de seu desenvolvimento em 2011, na cidade de Grão Mogol - que a questão da paisagem se afirmou como campo de interesse na minha trajetória. Naquele momento, eu já havia realizado intervenções em áreas verdes de modo a estabelecer conexões com a ambiência natural. Todavia, o desenvolvimento dos desenhos que constituem a série $\mathrm{Breu}$ consolidou a presença da abordagem da paisagem como conteúdo relevante na minha produção.

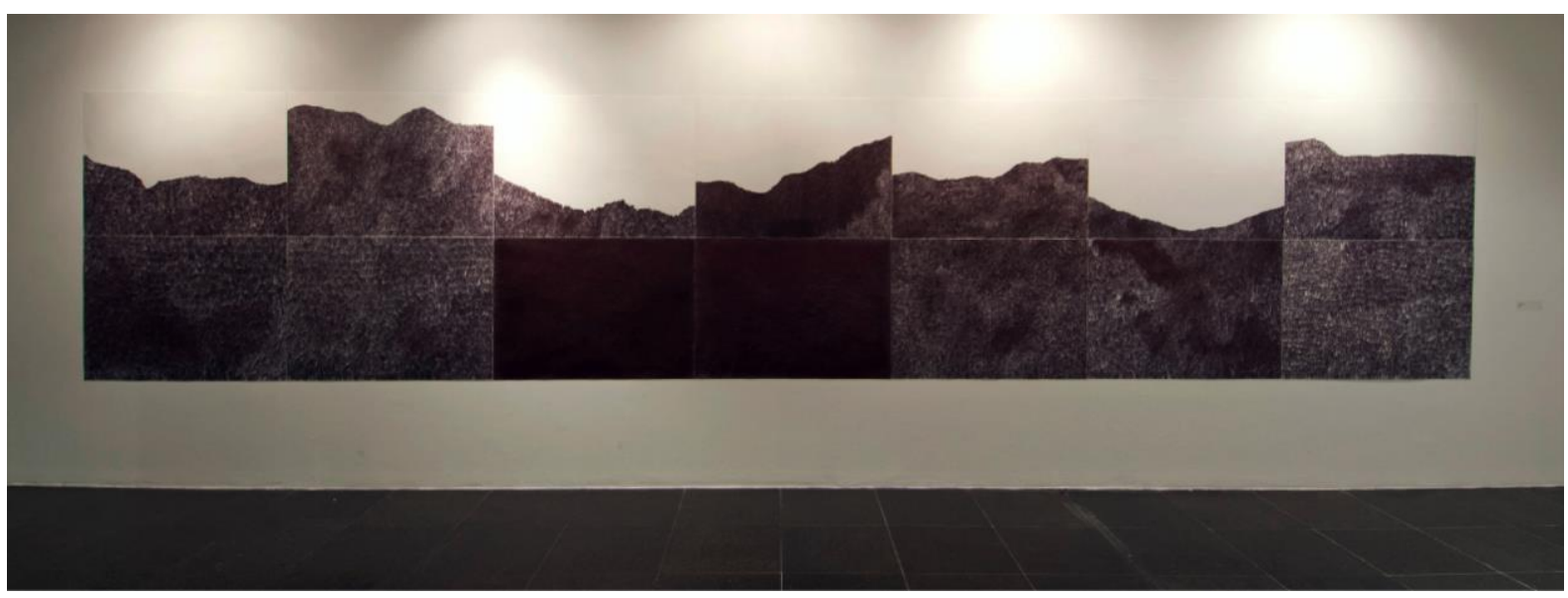

Júnia Penna. Breu, 2011. Caneta esferográfica s/ papel, 7 x 1,50 m. Fotografia Pedro Motta. 
A gênese do trabalho foi deflagrada por uma experiência que envolve o corpo como agente perceptivo de espaços e situações. Uma experiência que se constituiu por um processo de imersão artística na região do Norte de Minas Gerais. Essa vivência foi parte integrante do projeto de pesquisa Jequitinhonha: espaços, lugares e memórias IV. Os desenhos que configuram a série "Breu" foram gerados no período em que frequentei por quinze dias um pequeno abrigo, ou melhor, uma cabana construída com técnicas construtivas tradicionais, nos arredores da cidade de Grão Mogol, localizada nas encostas da Serra do Espinhaço V, região em que o relevo está sempre presente.

A temporada nesse "lugar-abrigo" - receptáculo e laboratório para experimentações, fruição de ideias, trocas de conhecimentos e desenvolvimento de trabalhos - possibilitou o contato direto com o ambiente natural, com todas as suas adversidades. Momentos de intenso calor eram atravessados por precipitações de fortes chuvas. Além das intempéries do clima, a vegetação local impunha a sua presença. O solo sobre o qual foi erguido a "cabana-atelier" era permeado por cactos da espécie coroa de frade e, com frequência, ficava nos pés de quem vagava desatento pelo local.

Habitar ou frequentar uma cabana permite uma experiência dinâmica e fluida entre a vida, que se desenrola na área interna, com os eventos que ocorrem do lado de fora. Gilles A. Tiberghien, em uma passagem do texto Natureza, Arte Contemporânea e Formas Arcaicas (2010), comenta o interesse dos artistas por esta forma construção vernacular:

[...] podem-se agrupar diversas práticas de artistas que trabalham na natureza sobre o motivo geral do abrigo, e mais particularmente da cabana, que é um ponto de encontro privilegiado entre arte e natureza dado que nos reenvia para as origens da arte e da civilização invocando ao mesmo tempo o desenvolvimento da espécie e do indivíduo. A experiência da cabana é de fato uma experiência da natureza, uma maneira de ser não ao abrigo do mundo, mas fora de si. A cabana, com efeito, não fecha nem protege aquele que a habita; pelo contrário, expõe-no a ele mesmo e à natureza concebida como exterioridade. ${ }^{\mathrm{VI}}$ 
0 ato de caminhar sozinha pelos arredores da "Cabana-Atelier" despertou em mim a consciência em relação às características geográficas do local escolhido para edificar a efêmera construção de madeira. Num determinado momento, ao longo do trajeto, me vi rodeada por imensos volumes rochosos próprio da geografia da região. Ao girar o corpo, constatei a presença desses volumes por todos os lados.

Por um instante, perceber que estava completamente circundada pelas montanhas da Serra do Espinhaço me trouxe a sensação de asfixia e um desejo enorme de trasnpor o anteparo estabelecido por esta cadeia rochosa. Ao mesmo tempo, irromperam uma série de memórias relativas a proximidade, que tenho com essa paisagem, pelo fato de viver em uma cidade que tem a Serra do Curral VII como marco geográfico mais representativo da região metropolitana de Belo Horizonte.

Na primeira versão apresentada o trabalho foi estruturado em 22 partes, em que cada uma delas possui $105 \times 75 \mathrm{~cm}$. As folhas de papel foram dispostas em duas fileiras e a configuração horizontal dos desenhos enfatiza a relação com o gênero tradicional da pintura de paisagem. Qual seria então a abordagem presente nessa proposição artística? Como o trabalho se aproxima e como se afasta das questões instauradas pela história da arte, visto que a intenção presente na realização da obra não se apoia em reproduzir a paisagem natural?

Ainda assim, mesmo sem se configurar como uma representação da paisagem Breu estabelece uma conexão com a existência de elementos naturais sobre a superfície da terra, seja em centros urbanos - onde a sua presença manifesta-se de modo contido -, seja em paisagem mais distantes, em que a natureza ainda se apresenta como elemento predominante.

No desenvolvimento do gênero da paisagem, a prática pictórica antecipou o surgimento do termo ao instaurar um conjunto de regras, que tornou possível a representação do ambiente natural por meio de convenções estéticas associadas à invenção da perspectiva. Convenções essas que permitiram a organização dos elementos no espaço pictórico em termos de escala, dimensão, proporção e profundidade. 
Anne Cauquelin aponta que a pintura tradicional do Ocidente, do século XV, concebeu a paisagem como análoga à natureza. Ou seja, a pintura de paisagem, estruturada por meio das leis da perspectiva, é dada como equivalente à própria natureza. A autora observa ainda que a imagem-paisagem, "construída sobre a ilusão da perspectiva, confunde-se com aquilo de que ela seria a imagem". VIII Isto é, a paisagem adere-se de tal modo à natureza, que o estatuto da imagem se transporta para o lugar do original.

Embora nessa abordagem exista uma aderência da ideia da paisagem, com a própria natureza, torna-se também compreensível que a paisagem é uma construção cultural fruto de transformações que trouxeram consigo a particularidade do indivíduo segregado do todo, do sentido de unicidade. Logo, a "paisagem ressurge da natureza", descola-se, torna-se uma parte, um recorte, sem, no entanto, desvencilhar-se da totalidade una do que se entende como natureza. Nesse contexto, Simmel comenta que

[...] a natureza, que no seu ser e no sentido profundo nada sabe da individualidade, graças ao olhar humano que a divide e das partes constitui unidades particulares, é individualizada para ser individualidade respectiva que apelidamos paisagem. ${ }^{\mathrm{IX}}$

Desse modo, a pintura da paisagem - apesar de ser uma representação figurada incita "o interesse por todos os aspectos da Natureza" e possui a "consistência de uma realidade para além do quadro, de uma realidade completamente autônoma". $\mathrm{x}$

Ainda no esteio da filósofa Anne Cauquelin, a autonomia da paisagem ocorre pelo fato de a estrutura perspectiva presente na representação pictórica ser incorporada também como uma estrutura do olhar. Dirigir os olhos para o ambiente natural, dentro desse paradigma, é estabelecer um ponto de vista situado fora dele. É delimitar um enquadramento, ordenar a visão. É ver em profundidade ao determinar proximidades e afastamentos. Como seria possível, então, que a representação da paisagem, fruto do olhar humano, artificialmente construída pelas leis da perspectiva - que recorta, individualiza e fragmenta em partes o todo - se confunda, para nós ocidentais, com a própria natureza? 
Na concepção de Simmel, a condição compartimentada da paisagem, que "constitui unidades particulares", em contradição com "a singularidade da unidade impartível da natureza", torna possível a ligação com o aspecto da totalidade na medida em que "cada porção só pode ser um ponto de passagem para as forças totais da existência". XI Sendo assim, a paisagem apresenta-se como uma particularidade da unidade individualizada pelo olhar do artista, que segmenta o ambiente ao redor, mas, ao mesmo tempo, instaura uma potência que "reata o fragmento à ideia do todo". Assim, os "limites inviolados" da paisagem abrigam no seu interior a amplitude dos acontecimentos naturais como também culturais.

É importante observar que o entendimento da paisagem como produção cultural não se restringe ao universo da estética:

[...] é preciso também fazer jus a outros olhares culturais lançados sobre a natureza, a outros universos de significação, a outros conceitos e a outras práticas que, tanto quanto a estética são investidas no território (investidas no sentido mais literal do termo).XII

Portanto, não se pode deixar de indagar sobre a ótica em relação ao tema proveniente de outros campos do conhecimento, como também da experiência espiritual e religiosa do ser humano, que, por vezes, confluem ou se afastam da visada da arte.

0 trabalho $\mathrm{Breu}$, de algum modo aproxima-se do gênero da paisagem caro à história da arte. Entretanto, o aspecto fracionado da configuração da imagem não remonta a um único ponto de vista. A sequência, constituída por partes desencontradas, interrompe a linearidade do horizonte. Esse desmembramento da imagem impede ao olhar o desenvolvimento de um percurso contínuo sobre a extensão formada pelos papéis distribuídos de modo sequenciado. A fluência do olhar, ao ser interrompida, distancia-se da atitude contemplativa característica de um espectador posicionado no topo de um belvedere. Os fragmentos embaralham a referência espaço-temporal e a imagem gráfica aproxima-se de um quebra-cabeça em que as peças não se encaixam.

Ver e olhar são atitudes distintas. No artigo Notas sobre a paisagem, visão e invisão (2008), a artista Karina Dias aponta o ver como um fenômeno fisiológico inerente à 
condição humana, pois "basta abrirmos os olhos para vermos". Diferente da ação de ver, o olhar manifesta-se como um "ato intencional"; portanto, apresenta-se como uma atitude de fixar os olhos em determinado ponto. É uma ação intencional que culmina em eleição. Nesse viés, Sérgio Cardoso aproxima a atitude de ver a um deslizamento horizontal, homogêneo e associado a "um movimento que nos lançaria numa visão panorâmica". 0 autor estabelece também uma conexão do olhar com a verticalidade que, por meio de um ato, "rompe com a linearidade do campo do ver, fissurando assim a sensação ilusória de totalidade". XIII

A paisagem montanhosa de Breu afirma-se como construção. Uma construção que instaura sentidos que ultrapassam a simulação de uma situação. Afirma-se em concordância com a concepção de Besse de que a noção de paisagem não se reduz à representação. A ligação com a realidade objetiva de reprodução da natureza encontra-se no trabalho desfacelada. No entanto, é desnecessário negar que existe um desejo de conexão com o contexto natural. 0 que seria, então, a natureza? Uma realidade ou uma concepção humana? Na perspectiva de Simmel:

[...] se designarmos algo de real como natureza, pretendemos então mencionar ou uma qualidade interna, a sua diferença perante a arte e ao factício, frente a algo ideal e histórico; ou que ele deve figurar como representante e símbolo daquele ser conjunto (.... ${ }^{\mathrm{XIV}}$

Correntes representativas do pensamento geográfico compreendem que "a natureza só existe porque é percebida, pensada e concebida pelo homem". O mundo compreendido pelo "desenvolvimento da sensibilidade e da razão humana torna-se real". Xv Porém, a questão vai além da relação humana com a "natureza". A terra com seus elementos - árvores, montanhas, vegetações, rios e mar - existe independente da percepção humana e da sua relação com eles. Sendo assim, a natureza deve ser compreendida:

[...] como criação do homem a partir de sua interação com o ambiente, mas sem por isso negar a sua realidade objetiva e pré-existente à humanidade, fator essencial para a existência do homem, que por vezes esquece que pertence ao mundo natural. $\mathrm{xVI}$

Jean-Marc Besse (2014) não concebe a natureza como criação humana. Na sua perspectiva o homem é um ser pertencente a ela. Desse modo, ela não é definida por 
ele nem para ele. Manifesta-se no próprio homem como também nos elementos que estão no seu entorno. 0 autor considera que a natureza, quando definida pelo homem, manifesta-se como cultura que traduz a maneira em que o ser humano percebe, organiza e concebe o mundo. De qualquer modo, é inegável que a natureza existe independente do ser humano e também que ele é parte integrante dela. A natureza está presente em sua própria fisiologia (MARIA, 2010).

0 ponto de vista recuado, caro à pintura tradicional da paisagem, evidencia a ruptura do sujeito com o objeto que mencionei anteriormente. Nos quadros de Peter Brueghel (1564-1638), o artista faz um comentário topográfico do mundo e também sobre a maneira como o homem utiliza o espaço terrestre. Nas suas pinturas o olhar distanciado é pontuado não apenas pela distribuição dos elementos, que estruturam a pintura a partir do plano do fundo, mas também na recorrência da presença de um observador localizado no primeiro plano, que dirige seu olhar em direção ao panorama terrestre. 0 recurso pictórico vai além de uma estrutura compositiva:

Não basta dizer que a paisagem bruegheliana é a expressão gráfica do antigo tema da Terra 'vista do alto'. Trata-se de entender que, nesta encenação, a superfície da Terra é deliberadamente representada como uma imagem a ser contemplada. A Terra (...); ela própria é concebida e apresentada como espaço do qual é preciso se afastar, ou em relação ao qual é preciso se elevar para apreendê-la como imagem. XvıI

Assim, a experiência que suscitou o desenvolvimento de Breu difere-se do recuo diante de uma situação. Ao me encontrar circundada pela cadeia de montanhas da Serra do Espinhaço percebi a potência da formação rochosa. Embora os primeiros estudos gráficos tenham partido de um olhar que vê ao longe, busquei traduzir no desenho uma experiência que apreende o mundo para além da visão. Na vivência do ambiente natural, ainda que a separação sujeito-objeto tenha permanecido, fui atravessada pela forte presença da serra. Uma experiência sensória proveniente de uma imersão no contexto do lugar. Mesmo distante e infinitamente pequena, em relação ao relevo do local, imprimiu-se a impressão de proximidade com uma estranha a sensação de perceber as montanhas quase de modo tátil. De ser tocada e de, ao mesmo tempo, tocar os volumes ao meu redor, ou melhor de ser impregnada por eles. 
Quanto a esses aspectos, Georg Simmel aponta a existência de uma correspondência entre o olhar da paisagem e a percepção estética. Correspondência essa que o autor considera o Stimmung da paisagem, conceito que compreende uma atmosfera e um modo particular de perceber, "uma tonalidade afetiva". Sendo assim, mesmo que acoplado à ideia de paisagem "exista" um a priori, ela é fruto de uma relação entre uma objetividade física e um olhar que a percebe, a apreende e a enquadra. Desse modo, a "atmosfera" de uma paisagem, no olhar de Simmel, "diz respeito à apreensão de algo que não está completamente isolado daquele que a percebe, e nem completamente no interior deste, como se fosse mera projeção de uma experiência interna, de uma história pessoal". xvIII

O stimmung da paisagem não seria então constituído por uma experiência objetiva. Vera Pallamin comenta que na experiência da paisagem existe "um momento fenomenológico constituído". XIX Portanto, a percepção da paisagem é fruto de um fenômeno em que a concretude do real é desfeita pelo olhar que impregna o "visto" de sentidos. A autora destaca ainda a aproximação entre o stimmung e o pensamento referente à estrutura da percepção, desenvolvido Merleau-Ponty, em que o autor descarta a separação sujeito-objeto, pois é no contato do corpo com o mundo que os sentidos são produzidos no território sensível.

Augustin Berque também concebe a paisagem como um evento relacional no qual ela "articula o lado objetivo do mundo, isto é, ela se reporta a objetos concretos os quais existem realmente ao redor de todos nós (pedras, montanha...) e o lado subjetivo, singular e íntimo de cada observador". xx

As relações que podem despontar no contato com o trabalho "Breu" surgem na esfera de uma presença corpo-mundo, que produz constantemente "sentido no sensível" (MERLEAU-PONTY, 1984). De acordo com Vera Pallamin, para MerleauPonty o "sentido do percebido provém de uma estruturação dinâmica e de conjunto estabelecida entre aquele que percebe seu ambiente, seu campo de presença". xxI Desse modo, as dimensões do trabalho - tanto na conformação horizontal, como na vertical - foram norteadas pela extensão, amplitude e potência da paisagem, que abarca o indivíduo em contato com ela. Não se trata de tentar reproduzir o 
irreproduzível, mas de construir, por meio da imagem gráfica, um território de presença em que os sentidos do trabalho podem ser apreendidos não apenas pelo campo da visão. Deslocar-se ao longo da horizontalidade do desenho ou postar-se diante dele, na configuração vertical, agrega a noção de proximidade. Paradoxalmente, amplitude e limite coabitam no território de abrangência do trabalho. Mais que um horizonte, o desenho apresenta-se como um anteparo para a visão.

Vivenciar o mundo promove experiências diferenciadas, às vezes, com tal intensidade, que deixam marcas profundas, ora na fisicalidade do corpo (que se consolidam como cicatrizes), ora sedimentam-se em camadas escondidas por trás de sentimentos e memórias. Em Grão Mogol a experiência foi da ordem da potência. 0 relevo acidentado fez-se presente desde a estrada que conduz à cidade. Recordome bem do momento em que a paisagem ao meu redor cristalizou-se, afirmou-se, deu-se a ver de fato diante de mim e, também, em mim. A paisagem, mais que prefigurar-se diante dos meus olhos, assegurou a existência da natureza.

É importante observar que a percepção da paisagem não nos dá jamais a ver por inteiro. Além da parte visível, existem outros lados. Ou melhor, vários lados daquela montanha, das montanhas, como também da montanha de Breu. Mesmo que a princípio o desenho possa apresentar-se apenas como uma "vista", trata-se, na verdade, de algumas "vistas". Não no sentido cezaniano ou cubista, que intenta dar a ver as várias faces de um mesmo objeto ou situação em um plano bidimensional. Diante do trabalho são possíveis vários pontos de vista, pois permite um campo amplo de projeções. Talvez isto explique a presença de áreas totalmente escuras, sem formas definidas, que participam da estrutura do desenho. Nessas partes existem apenas camadas e camadas de tinta, que, sobrepostas, formam uma extensa superfície preta.

A introdução de áreas escuras em meio a imagens, que remetem à montanhas e estruturas rochosas, pode ter sido motivada por uma situação vivida. No meio da estadia em Grão Mogol, por exemplo, deparei-me com um aviso preso na parede de uma das farmácias da cidade, informando que a Companhia Vale do Rio Doce estava 
convocando funcionários para trabalhar. Não consegui maiores informações sobre a nota ali depositada, mas, de imediato, constatei uma evidência: o norte de Minas era mais um dos focos de interesse para a extração mineral. Tal fato não seria novidade na região, pois a exploração de pedras faz parte do contexto e do imaginário da cidade, visto que a atividade de mineração de diamantes foi intensa na região, no século XVIII, quando se vendia pedras. Expressões como "fui tocaiado" ainda aparecem na fala de alguns moradores, pois nos primórdios da mineração de diamante a atividade era exercida muitas vezes de modo clandestino.

A atmosfera de se estar fora da lei ainda permeia o universo dos "homens" que comerciam, nos dias de hoje, cristais, entre outras pedras. Em 1786, o Administrador Geral comentou que

[...] os únicos senhores deste lugar são os garimpeiros. Eles fazem o que querem, e tem-se apoderado dos córregos diamantinos em grande multidão a muita força de armas, e estão tão desaforados, que até vão às povoações buscar mantimentos e traficam publicamente. XxII

Desse modo, assegurar o sentido de "natureza" na paisagem também aponta a transformação do ambiente "natural", isto é, aquelas que ocorrem por meio de acontecimentos, provenientes de processos naturais, como também modificações decorrentes da intervenção humana sobre a superfície da terra. Muitas vezes a atitude humana promove de modo agressivo a devastação dos meios naturais.

Retorno neste momento à questão da configuração de Breu no espaço expositivo como um dos elementos geradores de sentido, pois é importante comentar que o trabalho se encontra em processo de desenvolvimento e de transformação. Além de possuir mais de uma maneira de ocupar o ambiente, a cada apresentação novos desenhos podem ser agregados ou até mesmo retirados na versão. Exposta na Galeria da Faculdade de Artes Visuais da UFG, em 2013, a horizontalidade do trabalho foi substituída por uma ocupação vertical, que evidenciou a densidade do volume gráfico do desenho. 0 trabalho ganhou "peso". A disposição dos desenhos na galeria privilegiou a altura do pé direito da parede ao invés da extensão. Neste modo de ocupar o ambiente, a textura gráfica dos desenhos parecia confrontar fisicamente o visitante da mostra. 
A dimensão, como dado conceitual do trabalho, instaura uma possibilidade de contato em que o corpo é permeado pela situação na qual se encontra. 0 visitante é também caminhante. Nas duas configurações de $\mathrm{Breu}$, apresentadas até o momento, a intenção de constituir sentidos pelo envolvimento físico do espectador manifestase de modo afirmativo. Este envolvimento pretende ser ainda maior com a expansão do trabalho. De tempos em tempos realizo novos desenhos para serem agregados à obra. A intenção é, em algum momento, ocupar todo o ambiente expositivo com o trabalho. Do teto ao chão, de um lado a outro, de modo a preencher todas as paredes da sala de exposição.

Uma experiência que, por meio do envolvimento corporal, possa dar espaço para o surgimento de memórias, projeções, associações, enfim, construir um ambiente que proporcione ao espectador a possibilidade de conceber um olhar próprio, que amplie os sentidos da proposição artística.

A intenção de ocupar todas as paredes do ambiente expositivo com "relevos montanhosos" me sugere uma aproximação com o envolvimento do espectador presente na tecnologia do cinerama. Os únicos cinco filmes produzidos, entre 1952 e 1958, para o cinerama promovia um envolvimento do espectador no interior do filme. A imagem era projetada por três projetores sincronizados, formando um mesmo panorama na tela côncava, que cobria toda a parede. A potência visual era acompanhada pela intensidade de um som multidirecional. Os filmes registravam geograficamente os quatro cantos do mundo e proporcionavam ao espectador, sentado em uma poltrona de cinema, deslocar-se, ou melhor, "a viajar" por todos os continentes da superfície terrestre.

O cinerama propiciava uma imersão na imagem virtual da paisagem filmada. João Luiz Vieira comenta que a experiência proposta por essa tecnologia possibilitava o engajamento sensorial e, pode-se dizer também, corporal do espectador com o filme na medida em que era transportado para dentro da imagem tal como um personagem. Uma experiência que pode ser definida "como um verdadeiro realismo imersivo". XXIII 
A perspectiva aérea, tônica dos filmes destinados ao cinerama, incluía o impulso de querer dominar a paisagem por meio de um olhar que almejava abarcar todo o panorama mundial. Necessário ressaltar que esses filmes produzidos pelos Estados Unidos da América, após a Segunda Guerra Mundial, não deixam de incluir a visada de um país vitorioso.

O turismo virtual proposto pelos filmes inscrevia, em algum momento, o espectador diretamente no que João Luiz denomina de mobilidade "cinerámica", que tornava possível a sua "locomoção" por meio de aviões, carros, trens, barcos e até por mesmo gôndolas. Já a ideia de deslocamento presente no trabalho Breu está associada à experiência concreta do ato de caminhar.

No cinerama o sujeito movimenta-se "para o interior sempre expansivo da imagem" de um campo visual em profundidade, ao passo que na situação proposta em Breu o espectador desloca-se lado a lado com as "montanhas" gráficas. Diferente da experiência dos cinco filmes panorâmicos do cinerama, em que o sujeito "sobrevoa' a paisagem, diante dos desenhos o visitante é quase tocado por eles. Assim, a "silhueta montanhosa" não se refere à uma paisagem sublime, que remete à imagem de um paraíso natural. As texturas são densas e ásperas e a aparente ordem é quebrada pela presença abrupta de áreas escuras.

A paisagem das Minas, como também das Gerais, não se aproxima da realidade exuberante de algumas regiões do Brasil. No estado mineiro, que é parte interior do território brasileiro, ela é áspera e em momentos muito árida. Desse modo, a "silhueta montanhosa" do trabalho não remete à imagem de um paraíso natural. A densidade das texturas que constituem a massa gráfica quase gera aspereza e o "volume" pode ser um tanto opressor.

No campo de possibilidades associativas e da construção de sentidos não está em jogo o anseio de retorno ao estado selvagem da floresta, tal como na produção modernista brasileira em que o olhar voltado para a selva tornou-se uma possibilidade. Ou mesmo, como comenta João Luiz Vieira, um desejo nacionalista de "vencer a dominação cultural pela incorporação de dimensões nativas". 


\section{Corte/Mato/Mata}

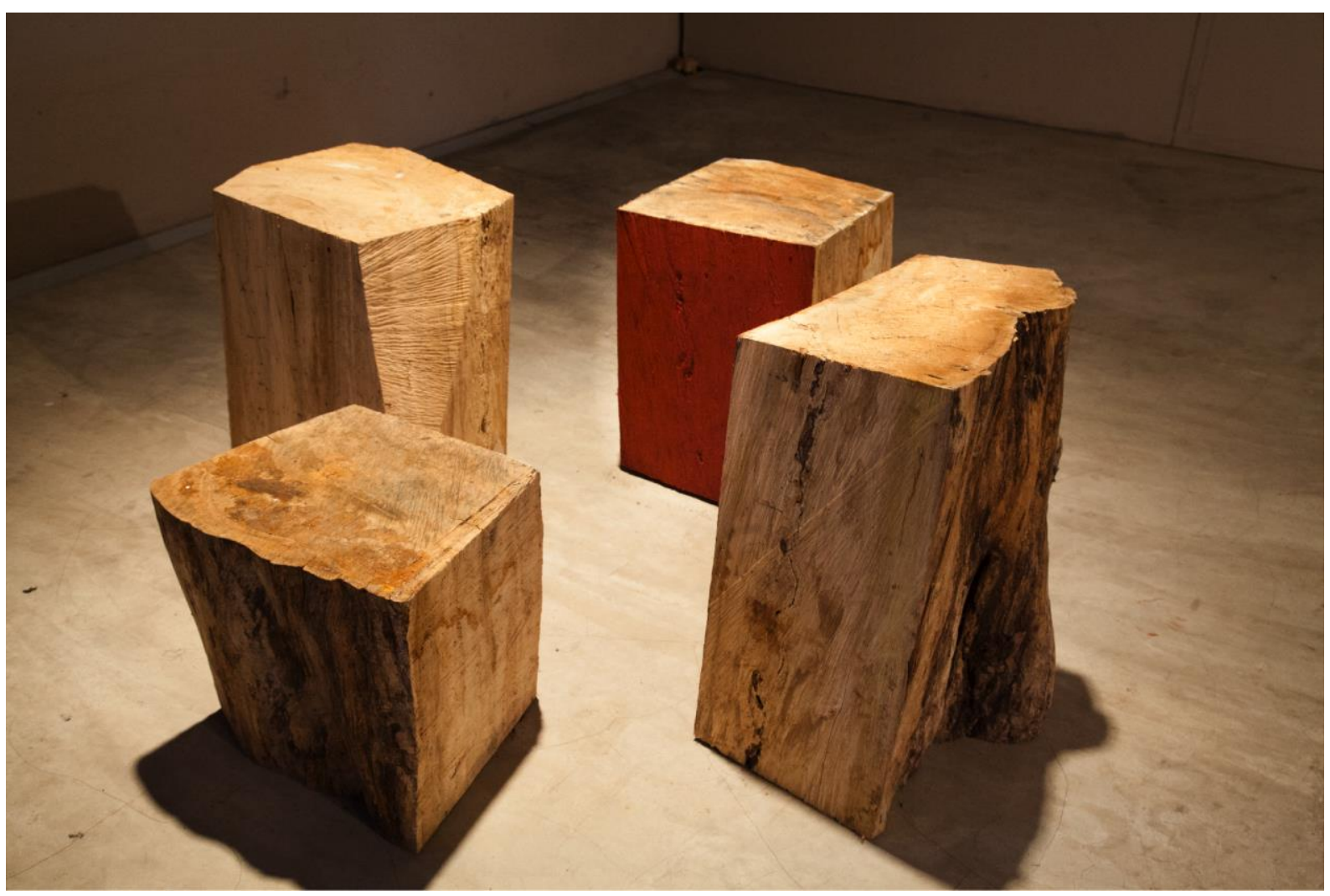

Júnia Penna. Corte/Mato/Mata, 2015. Grafite s/papel japonês e madeiras, dimensões variáveis. Fotografia Cláudia Tavares.

0 desejo de caminhar por paisagens em que a presença da vegetação seja preponderante atravessa a minha biografia. Caminhar sem grandes pretensões ou percorrer áreas verdes em busca de algo sem definição prévia, deslocar-me com olhar direcionado ou me deixar ser abarcada por alguma situação são atitudes que, em muitos casos, deflagram o surgimento de uma proposição artística ou instauram alguma questão a ser investigada. Caminhar sem compromisso pelas aleias do Jardim Botânico do Rio de Janeiro, mas atenta aos acontecimentos, proporcionou o surgimento das obras Corte/Mato/Mata e Aleia. 
Os trabalhos foram desenvolvidos no período da residência artística ProjetoPlantaBaixa, no Jardim Botânico da capital carioca, entre abril e agosto de 2015. No final da temporada de imersão eles foram apresentados em uma mostra coletiva no Espaço Tom Jobim. XxIV No processo de elaboração dos trabalhos, situações e ocorrências do cotidiano do Jardim Botânico foram observadas, apropriadas e retrabalhadas. A experiência deu origem a um conjunto de três esculturas e uma série de três desenhos destinados a ambientes interiores, que mencionam paisagens exteriores, processos de organização e manutenção do espaço.

É Importante ressaltar que os jardins, desde sua remota origem, carregam consigo a ideia de abrigarem a tranquilidade e de propiciar estados meditativos. Destinamse ao prazer e ao ócio. Separados do contexto da cidade guardam a presença ou memória da natureza. Apresentam-se como um dentro-fora, mas também como um fora-dentro. Nesse lugar-jardim, a natureza persiste. Contudo, a sua configuração é dada por meio de procedimentos seletivos, que elegem e modelam os elementos que participam da ambiência. Interposto entre a cidade e a amplitude do ambiente natural, salvaguarda os homens dos malefícios provenientes da selvageria dos centros urbanos e dos perigos da natureza. Dentro do limite de seus espaços o horizonte longínquo, característico da paisagem, não participa e a sua "fruição apresenta-se como parte de um pedaço escolhido da natureza, e não sua metáfora condensada". xxv

Como "dobra fora do mundo" o jardim, além de permitir o lazer e o exercício da liberdade, pode ser visto como um lugar de conhecimento. Anne Cauquelin destaca o "Jardim de Epicuro" como uma "metáfora para uma filosofia, sabedoria de uma vida ao abrigo das tempestades do mundo". Xxvi No campo do desenvolvimento do conhecimento, os Jardins Botânicos ocupam lugar de relevo. Seu surgimento, na Europa do século XVI, atrela-se ao estudo de ervas medicinais e, por consequência, formam-se as primeiras coleções de plantas com fins científicos.

O Jardim Botânico do Rio de Janeiro, desde sua fundação, em 1808, abrigou a diversidade de espécies vegetais. Mudas provenientes de outras colônias de 
portuguesas eram ali cultivadas. 0 interesse a priori era encontrar meios para aclimatar plantas de proveniência estrangeira, com o intuito de produzir rentabilidade econômica. Todavia, o processo de cultivo dos vegetais requer trabalho. Observações e experiências conduzem ao desenvolvimento científico, porém, nenhuma evolução seria possível sem um trabalho que envolvesse um dispêndio da força humana. A ação física é parte capital na produção do plantio. Ainda hoje, a manutenção do Jardim Botânico do Rio de Janeiro, mesmo utilizando a tecnologia avançada disponível, despende da força física por grande parte dos funcionários que ali trabalham. Foi então a atenção aos processos de manutenção do Jardim que desencadeou o surgimento do trabalho Corte/Mato/Mata.

No período da residência transitei várias vezes pelas aleias do Jardim Botânico sem objetivo predeterminado. No início apenas observava e experimentava os acontecimentos do lugar. Nas frequentes caminhadas, deparei-me com o corte de uma enorme árvore-de-contas, com o diâmetro aproximado de 1,40m, que se encontrava doente, na eminência de cair. 0 corte dessa árvore foi um empreendimento longo e exigiu grande esforço por parte dos funcionários envolvidos na empreitada. Mesmo com a ajuda eficaz do aparelho de motosserra era perceptível o enfrentamento físico necessário para a realização da missão: cortar a árvore.

Num primeiro momento, cortes horizontais fatiaram o tronco em rodelas. Em seguida, as lâminas espessas foram subdivididas em pedaços menores, com cortes precisos que deram origem a imprecisos cubos de madeira. Selecionei, então, alguns tocos cortados e recortados e pedi à equipe que fizesse algumas novas incisões, com a intenção apenas de evidenciar a inclinação sutil promovida pela direção oblíqua do corte. No entanto, a face externa do tronco foi preservada. Retiramos apenas as suas cascas, mantendo assim a memória da forma original e a textura da árvore. Nas demais faces, impôs-se a ação afirmativa dos talhos realizados, com a ajuda da máquina.

0 gesto decidido indica determinação. A dimensão e a solidez do tronco exigiram intensidade na força empregada na realização dos cortes, que pretendiam pôr a 
árvore abaixo. Nesse caso, uma atitude necessária. Os tocos de madeira recolhidos de árvores diversas deram origem ao trabalho Corte/Mato/Mata: um conjunto constituído por três esculturas em que as partes são organizadas na superfície do chão de modo a remeter à memória da árvore que lhes deu origem. Ora referem-se à verticalidade dos troncos, indicando o seu largo diâmetro, ora sugerem árvores estreitas, quando tombadas na posição horizontal. A disposição dos fragmentos e a distância entre eles evidenciam o corte. É importante destacar a presença do grafite ou da barra de óleo que em determinados momentos cobrem uma das faces dos fragmentos das árvores, que compõem o conjunto. Esses materiais são usados nas superfícies dos tocos, com o intuito de enfatizar o desenho produzido pela ação do motosserra na madeira.

Memórias e vestígios coexistem em Corte/Mato/Mata. 0 tempo se faz presente na matéria orgânica ao imprimir suas marcas. A árvore cresce e se desenvolve, mas também sofre com as oscilações do clima e com os acontecimentos ao seu redor. Tudo isso deixa rastros, que indicam sucessivos eventos ao longo do tempo. Entretanto, o registro do desenvolvimento das árvores, visível por meio de seus anéis de crescimento, é subtraído pela incisão da máquina, que grava na madeira o percurso da lâmina do motosserra de modo a transformar o desenho original do interior dos troncos. 0 que parece estar em jogo nesse conjunto de esculturas são potências dos elementos naturais, da ação do tempo e das atividades humanas.

As esculturas ocupam o plano horizontal e, ao mesmo tempo em que se comunicam entre si, estabelecem um diálogo com a série Aleia, constituída por três desenhos de grandes dimensões. No conjunto de desenhos, o grafite sobre papel japonês dá origem a imagens gráficas que, por sua escala e ocupação espacial, remetem à verticalidade das palmeiras-imperiais. 0 visitante que transita entre as esculturas situadas no chão é abarcado pela verticalidade dos desenhos, que podem promover de modo veloz um deslocamento do olhar em direção ao alto ou vice-versa. De qualquer modo, a ideia de que existe algo acima está presente no imaginário das palmeiras-imperiais, cujo plantio tornou-se comum no Rio de Janeiro, em meados do século XIX, afirmando-se como símbolo do Império. 
As proposições artísticas que realizo são frutos da minha vivência no mundo. Nesse sentido, busco abordar a paisagem não como objeto para a representação mas, como um meio para ativar memórias e experiências, como também um lugar que acolhe a projeção de imagens. É importante observar que a carga de informações presente nas proposições adquire novos contornos cada vez que os trabalhos que são expostos, pois ela "só adquire valor em relação à resposta de um receptor, e somente então se organiza realmente como um significado". O espectador é de fato um "centro ativo de uma rede de relações inesgotáveis". xxvII Ainda, a compreensão de um espectador que entra em contato com as obras em momentos distintos pode também se modificar, visto que "no mesmo rio entramos e não entramos; somos e não somos". xxvIII

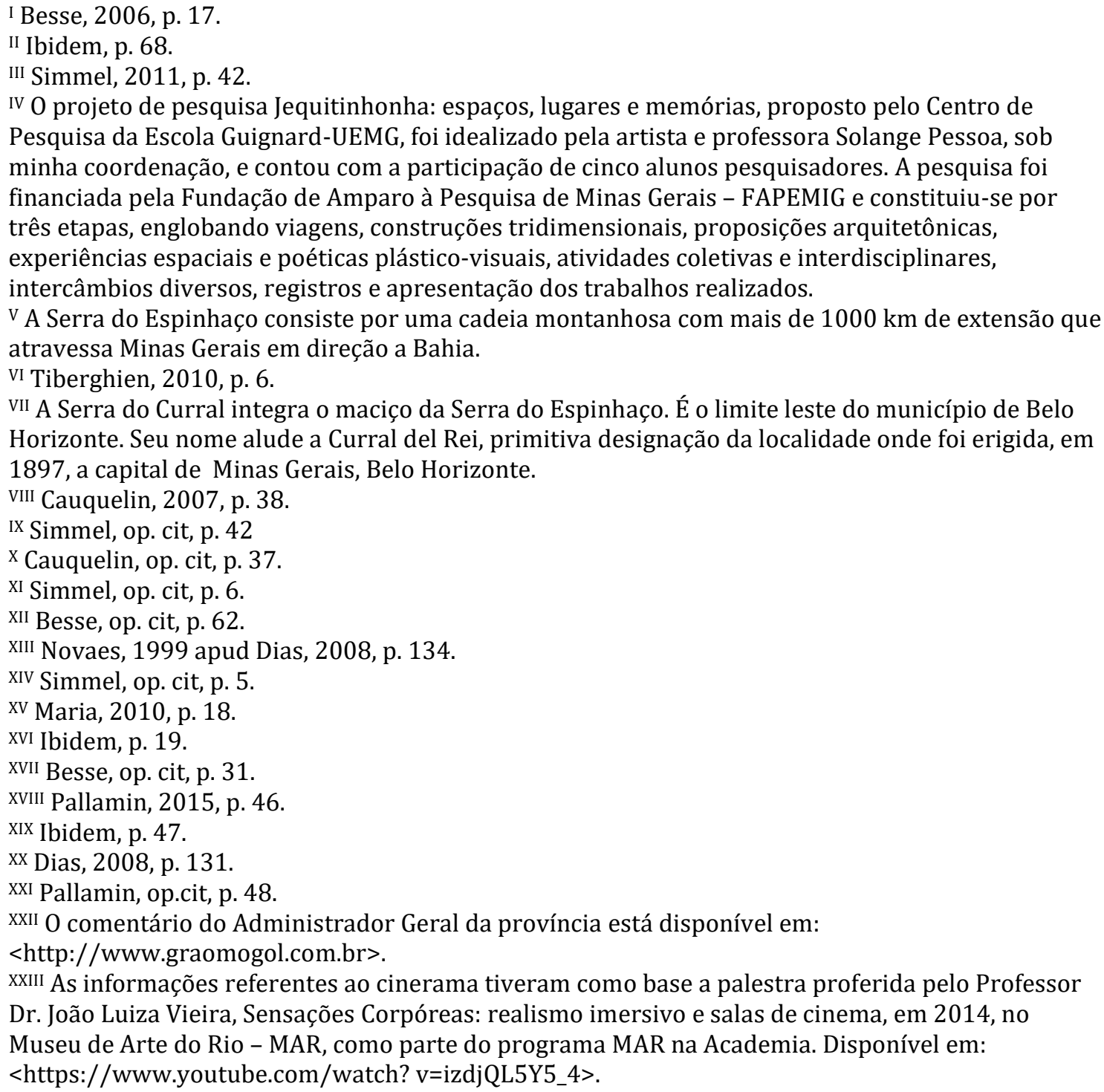


xxiv A residência artística ProjetoPlantaBaixa, sob coordenação de Malu Fatorelli, fez parte das atividades do doutorado. Participaram também as artistas e doutorandas Débora Mazloum, Nena Balthar e Susana Anágua.

xxv Cauquelin, op. cit, p. 65.

xxvi Cauquelin, op. cit, p. 62.

xxviI Eco, 1976, p.175.

xxviII Heráclito, 1980, fr.49a.

\section{REFÊRENCIAS BIBLIOGRÁFICAS}

BESSE, Jean-Marc. Ver a terra: seis ensaios sobre a paisagem e a geografia. Trad. Vladimir Bartalini. São Paulo: Perspectiva, 2006.

CARERI, Francesco. Walkscapes: o caminhar como prática estética. Trad. Frederico Bonaldo. São Paulo: Editora G. Gill, 2013.

CAUQUELIN, Anne. A invenção da paisagem. Trad. Marcos Marciolino. São Paulo: Martins Fontes, 2007.

DIAS, Karina. Notas sobre paisagem, visão e invisão. In: Visualidades. Revista do Programa de Pós-Graduação de Mestrado em Cultura Visual - FAV / UFG. [Online], n. 1 e 2, v. 6, p. 129-141, 2008. Disponível em: <https://www.revistas.ufg.br/VISUAL>. Acesso em: 20 nov.2017.

EC0, Humberto. Obra Aberta. Trad. Sebastião Uchoa Leite. São Paulo: Editora Perspectiva, 1976.

GRÃO Mogol. Comentário do Administrador Geral da província. Disponível em: <http:// www.graomogol.com.br/>. Acesso em: 06 mar.2018.

HERÁCLITO. Fragmentos. Edição bilíngue. Trad. Emmanuel Carneiro Leão. Rio de Janeiro: Edições Tempo Brasileiro, 1980.

MARIA, Yancy Ladeira. Paisagem: entre o sensível e o factual. Uma abordagem a partir da geografia cultural. Dissertação de mestrado. Área de concentração: Geografia Humana. Faculdade de Filosofia, Letras e Ciências Humanas - USP/SP, 2010.

MERLEAU-PONTY, Maurice. Fenomenologia da Percepção. São Paulo: Martins Fontes, 1994.

MUSEU de arte do Rio. Curso O Espectro Cinematográfico - Prof. João Luiz Vieira. Publicado em 29 de dez de 2014. Disponível em: <https://www.youtube.com/watch?v=izdj QL5Y5_4>. Acesso em: 20 nov.2017.

PALLAMIN, Vera. Fenomenologia, paisagem e arte contemporânea. In: Paralaxe, [online] v. 3, n. 2, p. 44-61, 2015. Disponível em: <https://revistas.pucsp.br/index.php/paralaxe/about/ editorialTeam>. Acesso em: 14 dez.2017. 
SIMMEL, Georg. Filosofia da Paisagem. Universidade da Beira Interior. Covilhã, 2009. In: SERRÃO, Adriana Veríssimo (Coord.). Filosofia da Paisagem - uma antologia. Lisboa, Trad. A. V. Serrão et al.. Centro de Filosofia da Universidade de Lisboa, 2011.

TIBERGHIEN, Gilles A. Natureza, Arte Contemporânea e Formas Arcaicas. Trad. José Casquilho. Dicionário Crítico de Arte, Imagem, Linguagem e Cultura. Disponível em: <http://www.arte-coa.pt>. Acesso em: 04 out.2017.

Recebido em: 16/11/2018

Aprovado em: 18/11/2018 